\title{
Threat of unionization and nonunion employment
}

\author{
Pablo Ruiz-Verdú*
}

Universidad Carlos III de Madrid, Department of Business Administration, Calle Madrid, 126. 28903, Getafe, Madrid, Spain

\begin{abstract}
If nonunion employers set both wages and employment strategically to forestall unionization, the threat of unionization, despite raising wages, increases employment above competitive levels, in contrast with the prediction of standard models.
\end{abstract}

Keywords: Threat of unionization; Employment determination

JEL classification: J23; J30; J51

\section{Introduction}

According to the standard union threat model of wage determination, nonunion employers strategically raise wages when faced with the threat of union organization. The higher wages, in turn, reduce nonunion employment, as nonunion firms move up along their labor demand curves. ${ }^{1}$

While acknowledging that nonunion employers will take into account the effect of their wage choices on workers' incentives to organize, standard union threat models effectively assume that those same employers disregard the effect that their employment choices may have on workers' unionization decision. In this paper, I develop a model in which nonunion firms set both wages and employment strategically when faced with a threat of unionization. The model shows that if nonunion firms take into

\footnotetext{
* Tel.: +34 916245801; fax: +34 916249607.

E mail address: pablo.ruiz@uc3m.es.

${ }^{1}$ See Farber (2005) for a recent version of the union threat model and Ehrenberg and Smith (2005) for a textbook exposition. Pencavel (1991, ch. 6) offers a more general analysis of the interaction between union and nonunion sectors.
} 


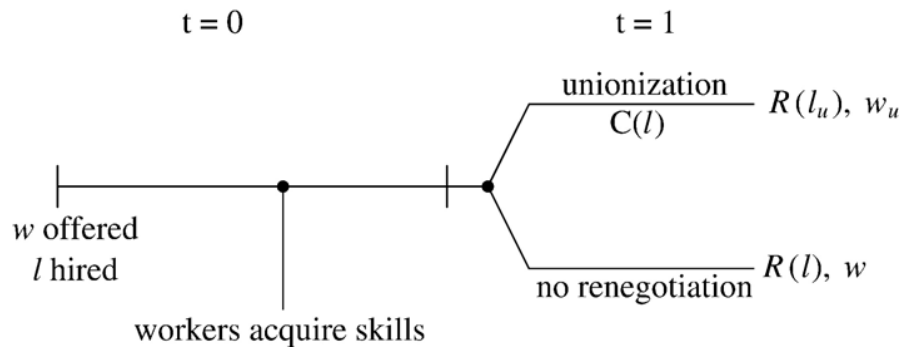

Fig. 1. Sequence of events.

account the effect of their employment choices on workers' incentives to unionize, the prediction of the standard threat model is reversed: instead of reducing employment, the threat of unionization increases employment above competitive levels.

\section{Setup}

Consider a nonunion firm that hires $l$ workers from a pool of identical workers with reservation wage $\bar{w}$ and offers these workers a wage $w$ to be paid after production takes place. Through on-the-job learning, the $l$ employees accumulate firm-specific skills, thus becoming more valuable for the firm than alternative workers. If they are not satisfied with the wage $w$ initially offered by the firm, employees can unionize to renegotiate the wage so as to capture part of the quasi-rents generated by their firm-specific skills. ${ }^{2}$ Unionization, however, entails organization costs $C(l)$ for workers. ${ }^{3}$ If workers unionize, collective bargaining takes place, resulting in employment $l_{u} \leq l$ and a wage $w_{u}$.

At the end of the period, revenues are generated and wages paid. The revenues generated by incumbent workers are described by the function $R$, with $R^{\prime} \geq 0$ and $R^{\prime \prime}<0$. For simplicity, it is assumed that the firm's revenues would be zero if it employed workers with no firm-specific skills. Fig. 1 displays the timeline of the model.

\section{Collective bargaining}

When setting wages and employment, the firm will try to predict the effect of its choices on workers' incentives to unionize. These incentives, in turn, depend on the wage and employment levels that would result if workers unionized and bargained collectively with the firm. Therefore, to solve the model, I proceed by backward induction and first analyze the collective bargaining stage that takes place if workers unionize.

\footnotetext{
${ }^{2}$ The assumption that workers have no individual bargaining power is made only for simplicity: none of the results would change qualitatively if we allowed for individual bargaining power, as long as employees' bargaining power is greater if they bargain collectively.

${ }^{3}$ These costs reflect the time and effort workers need to put into organizing (or the fees and dues paid to union officials if these activities are delegated to an existing union) and the costs stemming from potential retaliatory measures that employers may take to fight the unionization attempt. See Kleiner (2001) for a recent assessment of these costs and their influence on unionization.
} 
Union-management bargaining is modelled by means of the commonly-used monopoly union model. According to this model, the union imposes its wage demands on the employer, who then sets employment at will. I assume that the union's objective is to maximize the total rents accruing to its members, which is also one of the most usual assumptions in the literature:

$$
U\left(w_{u}, l_{u}\right)=l_{u}\left(w_{u}-\bar{w}\right)
$$

As I discuss in Section 5, the particular choice of bargaining model or union objective function does not play any essential role in deriving the results.

The well-known outcome of the monopoly union model is the wage-employment pair on the marginal revenue product curve that yields the highest rents to the union (see Booth, 1995, ch. 4). Below, I extend the usual model to account for the restriction that the level of skilled employment resulting from the collective bargaining process $\left(l_{u}\right)$ cannot be greater than the number of workers with specific skills $(l)$. Therefore, once the union has set a wage $w_{u}$, the firm sets $l_{u} \leq l$ such that $R\left(l_{u}\right)-w_{u} l_{u} \geq R\left(l_{u}^{\prime}\right)-w_{u} l_{u}^{\prime}$, for any $l_{u}^{\prime} \leq l$.

The union's problem can then be stated as follows: ${ }^{4}$

$$
\begin{aligned}
& \max _{l_{u}, w_{u}} l_{u}\left(w_{u}-\bar{w}\right) \\
& \text { s.t. } l_{u} \leq l \\
& R\left(l_{u}\right)-w_{u} l_{u} \geq R\left(l^{\prime}{ }_{\mathrm{u}}\right)-\mathrm{w}_{\mathrm{u}} l_{\mathrm{u}} \mathrm{V}, \text { for any } l_{\mathrm{u}}^{\prime} \leq 1
\end{aligned}
$$

Let $w_{u}(l)$ and $l_{u}(l)$ denote the solutions to this problem, and let $\prod_{u}(l) \equiv R\left(l_{u}(l)\right)-w_{u}(l) l_{u}(l)$. The following lemma describes the properties of $w_{u}(l), l_{u}(l)$ and $\Pi_{U}(l)$ (the proof is in the Appendix):

Lemma 1. In the monopoly union model:

(A) $\mathrm{w}_{\mathrm{u}}(l)$ is nonincreasing in $l$.

(B) There exists a level of membership $1_{\mathrm{u}}^{*}$ such that:

B.1) For $1 \leq 1_{\mathrm{u}}^{*}, 1_{\mathrm{u}}(l)=1$

(B.2) For $1 \geq 1_{u}^{*}, 1_{\mathrm{u}}(l)=l_{u}^{*}$ and $w_{u}(l)=w_{u}\left(l_{u}^{*}\right)$.

(C) $\prod_{\mathrm{U}}(l)$ is increasing in $l$ for $l<l_{u}^{*}$, and constant in $l$ for $l>l_{u}^{*}$.

Result (A) implies that a larger membership will induce the union to accept a lower wage in exchange for greater employment. Result (B) shows that for low levels of initial employment, the negotiated outcome implies the employment, the union is not willing to concede any further reduction in wages and instead accepts some unemployment (B.2). Result (B) thus implies that $l_{u}(l)$ is nondecreasing in $l$. Finally, result $(\mathrm{C})$ means that the profits of a unionized firm are nondecreasing in initial employment. This makes sense: if the union raises wages and reduces employment, increasing initial employment will, according to properties (A) and (B) counteract both effects, and should, thus, tend to increase profits. Note, however, that (A) and (B) do not imply (C).

\footnotetext{
${ }^{4}$ This formulation is equivalent to one in which the union selects $w_{u}$ to maximize $l_{u}\left(w_{u}, l\right)\left(w_{u} \bar{w}\right)$, where $l_{u}\left(w_{u}, l\right)$ is the solution to the firm's employment choice problem given $w_{u}$ and $l$.
} 


\section{Wage setting and union avoidance}

Let $w_{T}(l)$ denote worker's expected payoff from unionization (bet of organization costs).

$$
w_{T}(l) \equiv \frac{l_{u}(l)}{l} w_{u}(l)+\left(1-\frac{l_{u}(l)}{l}\right) \bar{w}-\frac{C(l)}{l}
$$

For any employment choice, $l$, the firm has to offer a wage at least as high as $w_{T}(l)$ if it wants to remain nonunion. If $w_{T}(l) \leq \bar{w}$, the firm sets $\bar{w}$ and avoids unionization. If $w_{T}(l)>\bar{w}$ and the firm offers a wage below $w_{T}(l)$, workers unionize and profits are $\left.\prod_{U}(l)=R\left(l_{u}(l)\right)-w_{u}(l) l_{u}(l)\right)$. If the firm offers $w_{T}(l)$, and workers accept, profits are:

$$
\Pi\left(l, w_{T}(l)\right)=R(l)-l w_{T}(l)=R(l)-w_{u}(l) l_{u}(l)-\bar{w}\left(l-l_{u}(l)\right)+C(l)
$$

For $l_{u}^{*}$ as defined in Lemma 1, it follows from properties (B.2) and (C) in Lemma 1 that $\prod_{U}\left(l_{u}^{*}\right) \geq \prod_{U}(l)$ for any $l$. Moreover, $l_{u}\left(l_{u}^{*}\right)=l_{u}^{*}$ and $w_{T}\left(l_{u}^{*}\right)=w_{u}^{*}-\frac{C\left(l_{u}^{*}\right)}{l_{u}^{*}}$, so $\Pi\left(l_{u}^{*}, w_{T}\left(l_{u}^{*}\right)\right)=R\left(l_{u}^{*}\right)-l_{u}^{*} w^{u *}+$ $C\left(l_{u}^{*}\right)>R\left(l_{u}^{*}\right)-l_{u}^{*} w^{u *}=\Pi_{U}\left(l_{u}^{*}\right)$. Therefore if $l^{*}$ is the optimal employment level, it follows that $\Pi\left(l^{*}, w_{T}\right.$ $\left.\left(l^{*}\right)\right) \geq \Pi\left(l_{u}^{*}, w_{T}\left(l_{u}^{*}\right)\right)>\Pi_{U}(l)$ for any $l$. In words, the firm can guarantee higher profits by setting $l=l^{*}$ and $w=w_{T}\left(l^{*}\right)$ than by setting any employment-wage pair that leads to unionization, Therefore, we obtain the following result:

Proposition 1. In equilibrium, the firm offers

$$
w^{*}\left(l^{*}\right)=\max \left\{w_{T}\left(l^{*}\right), \bar{w}\right\},
$$

where $l^{*}$ is the optimal employment level, and workers accept the wage offer.

As proposed by the standard union threat view, in equilibrium, firms raise wages above $\bar{w}$ to eliminate workers' incentives to organize. Only if $C(l)$ is sufficiently large will the union threat become ineffective, and the wage remain at the competitive level.

\section{Employment determination}

Expression (4) highlights that the wage necessary to forestall unionization depends on the level of employment, $l$. Therefore, the firm should take this influence into account when choosing its optimal employment level.

If $l<l_{u}^{*}$, Property (B.1) in Lemma 1 implies that $l_{u}(l)=l$, so that $w_{u}^{*}(l)=w_{u}(l)-\frac{C(l)}{l}$ and $\Pi\left(l, w^{*}(l)\right)=R(l)-w_{u}(l) l+C(l)=\Pi_{U}(l)+C(l) .{ }^{5}$ Therefore, for low levels of employment, the maximum profit that the firm can obtain while avoiding unionization is equal to the profit the firm would obtain if workers unionized plus the costs that workers would have to incur so as to unionize. By property (C), we know that $\prod_{U}(l)$ is increasing in $l$ for $l<l_{u}^{*}$. Therefore, if $C$ is nondecreasing in $l, \Pi\left(l, w^{*}(l)\right)$ will also be increasing in $l$ for $l<l_{u}^{*}$. It follows that if $l^{*}$ denotes the firm's optimal employment choice, $l^{*} \geq l_{u}^{*}$.

\footnotetext{
${ }^{5}$ To simplify the argument, I assume that $w^{*}(l) \quad w_{T}(l)>\bar{w}$ for the relevant range of $l$.
} 
Now, for $l \geq l^{*}, l_{u}(l)=l_{u}^{*}$ and $w^{*}(l)=\frac{l_{u}^{*}}{l} w_{u}^{*}+\left(\frac{l-l_{u}^{*}}{l}\right) \bar{w}-\frac{C(l)}{l}$, so that the wage bill is $w^{*}(l) l=$ $l_{u}^{*} w_{u}^{*}+\left(l-l_{u}^{*}\right) \bar{w}-C(l)$. Notice that, if we abstract from the last term, this expression implies that, for any $l \geq l_{u}^{*}$, if the firm wants to hire an extra worker while avoiding unionization, it only has to increase the wage bill by $\bar{w}$. The reason is that, when $l \geq l_{u}^{*}$, any additional worker hired only increases workers' total payoff in case of unionization by $\bar{w}$ : since the new hire would not affect the union-negotiated wage or employment level, it would only increase the number of skilled workers who lose their job - and, thus, earn $\bar{w}-$ after unionization. Therefore, for $l \geq l_{u}^{*}, \Pi\left(l, w^{*}(l)\right)=R(l)-w^{*}(l) l=R(l)-l_{u}^{*} w_{u}^{*}-\left(l-l_{u}^{*} \bar{w}+C(l)\right.$, so:

$$
\Pi^{\prime}\left(l, w^{*}(l)\right)=R^{\prime}(l)-\bar{w}+C^{\prime}(l)
$$

In the absence of a union threat, the firm would choose the level of employment $l_{c}$ such that $R^{\prime}\left(l_{c}\right)=\bar{w}$. It follows from this last expression and Eq. (7) that, as long as $C^{\prime} \geq 0, \Pi^{\prime}\left(l_{c}, w^{*}\left(l_{c}\right)\right) \geq 0$ and, by strict concavity of $R, \Pi^{\prime}\left(l, w^{*}(l)\right)>0$ for $l<l_{c}$. Therefore, $l^{*} \geq l_{c}$, and $l^{*}>l_{c}$ if $C^{\prime}\left(l_{c}\right)>0$. The following proposition summarizes the argument.

Proposition 2. Let $l^{*}$ be the optimal employment level and $l_{c}$ the competitive employment level. Then $l^{*} \geq l_{c}$.

It is worth noting that the overemployment result in Proposition 2 does not depend on the specific choice of bargaining model. It can be shown that the result holds for more general specifications of the union's objective function and for a large family of bargaining models that includes the two other main collective bargaining models, namely the right-to-manage and the efficient bargaining models. ${ }^{6}$ What drives the overemployment result are properties (A)-(C) in Lemma 1, which, essentially, follow from the assumption that the marginal revenue product of labor is decreasing in the level of employment.

Although the standard union threat model predicts that employment will fall as a consequence of the threat of unionization, it should be noted that there is a precedent for the positive threat effect in Proposition 2. Using a different modelling strategy (in which coalitions of workers can form a union and select a wage-employment pair from a set of exogenously-given possible bargaining outcomes), Dickens (1986) showed in a working paper that the threat of unionization could lead to an increase in employment under certain conditions regarding the ability of coalition workers to discriminate against noncoalition workers.

\section{Conclusion}

It has long been recognized that the threat of unionization is likely to affect nonunion firms' wage policies. In particular, union threat models have proposed that nonunion firms will increase wages above competitive levels to dissuade workers from joining unions. In this paper, I argue that the same logic applies to employment choices: nonunion firms should set their employment levels taking into account the impact of their choices on workers' incentives to organize. To the extent that employers do take into account the effect of employment on prospective unionization, I show that the threat of unionization, despite raising wages as in

\footnotetext{
${ }^{6}$ For a review of theses models, see Booth (1995, ch. 5).
} 
standard union threat models, will increase employment above the competitive level, in contrast to the prediction of those models.

\section{Acknowledgements}

The author thanks Edward Lazear, Robert McMillan, John Pencavel and Steve Tadelis for extremely helpful discussions. The usual disclaimer applies. The financial support of Spain's Ministry of Education and Science (SEJ2005-06655/ECON) is gratefully acknowledged.

\section{Appendix A}

Proof of Lemma 1. The standard monopoly union problem with no restrictions on $l_{u}$ can be stated as:

$$
\begin{aligned}
& \max _{l_{\mathrm{u},}, w_{u}} l_{u}\left(w_{u}-\bar{w}\right) \\
& \text { s.t. } R\left(l_{u}\right)-w_{u} l_{u} \geq R\left(l_{u}^{\prime}\right)-w_{u} l_{u}^{\prime}, \quad \text { for any } l_{u}^{\prime} \leq 0
\end{aligned}
$$

Concavity of $R$ implies that the restriction can be replaced by the F.O.C.: $R^{\prime}\left(l_{u}\right)=w_{u}$, so problem $\left(P_{A}\right)$ can be rewritten as

$$
\max _{l_{u}} l_{u}\left(R^{\prime}\left(l_{u}\right)-\bar{w}\right)
$$

Making the standard assumption that problem $\left(P_{A}^{\prime}\right)$ is concave, its solution, $l_{u}^{*}$, is given by

$$
R^{\prime}\left(l_{u}^{*}\right)-\bar{w}+l_{u}^{*} R^{\prime \prime}\left(l_{u}^{*}\right)=0
$$

Let $w^{*} \equiv R^{\prime}\left(l_{u}^{*}\right)$ and let $l_{c}$ be defined by $R^{\prime}\left(l_{c}\right)=\bar{w}$. Strict concavity of $R$ implies that $w_{u}^{*}>\bar{w}$ and $l_{u}^{*}<l_{c}$. If $l_{u}$ is constrained to lie below $l$, the union solves problem $\left(P_{B}\right)$ :

$$
\begin{aligned}
& \max _{l_{u}, w_{u}} l_{u}\left(w_{u}-\bar{w}\right) \\
& \text { s.t. } l_{u} \leq l \\
& R\left(l_{u}\right)-w_{u} l_{u} \geq R\left(l_{u}^{\prime}\right)-w_{u} l_{u}^{\prime}, \quad \text { for any } l_{u}^{\prime} \leq 1
\end{aligned}
$$

For any $w_{u} \leq R^{\prime}(l), R^{\prime \prime}<0$ and Eq. (10) imply that $l_{u}=l$. Therefore, it cannot be optimal for the union to set $w^{u} \leq R^{\prime}(l)$, (since $w_{u}=R^{\prime}(l)$ guarantees the same level of employment). Now, if the union sets $w_{u} \geq R^{\prime}(l)$ for any $l$, then $l_{u}$ will satisfy $R^{\prime}\left(l_{u}\right)=w_{u}$, so the union's problem becomes:

$$
\begin{aligned}
& \max _{l_{u}} l_{u}\left(R^{\prime}\left(l_{u}\right)-\bar{w}\right) \\
& \text { s.t. } l_{u} \leq l
\end{aligned}
$$

Problem $\left(P_{B}^{\prime}\right)$ is identical to problem $\left(P_{A}^{\prime}\right)$ with the addition of constraint (9). Therefore, if $l_{u}^{*}$ satisfies Eq. (9), then it is a solution to problem $\left(P_{B}^{\prime}\right)$. Thus $l_{u}(l)=l_{u}^{*}$ and $w_{u}(l)=w_{u}^{*}$ for $l \geq l_{u}^{*}$, proving (B.2). Now, 
the concavity of problem $\left(P_{A}^{\prime}\right)$ ensures that $R^{\prime}\left(l_{u}\right)-\bar{w}-l_{u} R^{\prime \prime}\left(l_{u}\right)>0$ for $l_{u}<l_{u}^{*}$. That is, the marginal benefit for the union of increasing employment is positive for $l_{u}<l_{u}^{*}$. Therefore, for $l<l_{u}^{*}, l_{u}(l)=l$ and $w_{u}(l)=R^{\prime}(l)$, proving (B.1). (A) follows from the concavity of $R$ and the fact that for $l<l_{u}^{*}, w_{u}(l)=R^{\prime}(l)$, and, for $l \geq l_{u}^{*}$, $w_{u}(l)=w_{u}^{*}$.

Finally, note that for $l<l_{u}^{*}, \prod_{U}(l)=R\left(l_{u}(l)\right)-l_{u}(l) w_{u}(l)=R(l)-l R^{\prime}(l)$, which is increasing in $l$ due to the concavity of $R$; and, for $l \geq l^{*}, \prod_{U}(l)=R\left(l_{u}(l)\right)-l_{u}(l) w_{u}(l)=R\left(l^{*}\right)-l^{*} R^{\prime}\left(l_{u}^{*}\right)$, which is constant in $l$. This proves (C).

\section{References}

Booth, A.L., 1995. The Economics of the Trade Union. Cambridge University Press, Cambridge.

Dickens, W.T., 1986. Wages, Employment, and the Threat of Collective Bargaining by Workers. NBER Working Paper, vol. 1856.

Ehrenberg, R.G., Smith, R.S., 2005. Modern Labor Economics, Ninth ed. Addison Wesley, Boston.

Farber, H.S., 2005. Nonunion wage rates and the threat of unionization. Industrial and Labor Relations Review 58, 335352.

Kleiner, M.M., 2001. Intensity of management resistance: understanding the decline of unionization in the private sector. Journal of Labor Research 22, 519540.

Pencavel, J.H., 1991. Labor Markets Under Trade Unionism: Employment, Wages and Hours. Basil Blackwell Inc., Oxford. 